\title{
LITERATURA DISTÓPICA, ONTEM E HOJE: UM PERCURSO NA HISTÓRIA E NA FICÇÃO
}

\author{
Valéria da Silva Medeiros ${ }^{1}$ \\ Andrea Martins Lameirão Mateus ${ }^{2}$
}

Resumo: Este artigo reflete sobre o renovado interesse pela distopia diante do cenário econômico e político mundial, partindo de reflexões de Antonio Candido (1995) e Erich Fromm (1961) sobre o otimismo diante das possibilidades de avanço tecnológico para a solução de problemas que permitiriam o progresso moral e material do indivíduo e da humanidade que animou o século XVIII. No século XIX, a ficção científica estava seus primeiros passos através de contos de antecipação científica e a constatação do aumento progressivo da tecnologia versus o crescimento da desigualdade social encontraria sua expressão na distopia. Já distante do cenário do pós Segunda Guerra Mundial, universos diegéticos que expressam uma visão negativa de um futuro muito próximo autoritário e baseados na controle da sociedade e na supressão das liberdades individuais ganham espaço seja na literatura, no cinema, nas séries para a TV ou na adaptação com enorme sucesso para TV como é o caso exemplar de O conto da aia, de Margareth Atwood, de 1985, que utilizaremos como modelo deste tipo de distopia.

Palavra-chave: Distopia; Humanismo Científico; Barbárie.

\section{Dystopic Literature, then and now: an itinerary in History and Fiction}

Abstract: The present article reflects the renewed interest for dystopian fiction as a response to our economical and political scenario, from reflections found in Antonio Candido (1995) and Erich Fromm (1961) comments on the optimistic views of technological advancements and humanity, that animated the public debate in the 18th Century. In the 19th Century, Science Fiction was in its first steps and the observation of the increasing progress in technology versus the increase of social disparity would find its expression in dystopia. Already distant from the post-World War II, the diegetic scenarios that express a negative view of a very near authoritarian future, based in the control of society and suppression of individual liberties, would gain space in the literary world, in cinema, in TV series. Such is the case of the successful adaptation of Margareth Atwood's The Handmaid's Tale (1985), a novel we use as an example of this kind of dystopia.

Key-words: Dystopia, Humanism, Barbarism

1 Professora adjunta de Teoria da Literatura na Licenciatura em Letras e docente no Programa de Pós-Graduação em Ensino de Língua e Literatura da Universidade Federal do Tocantins e no Mestrado Profissional em Rede - PROFLETRAS, no Campus de Araguaína da Universidade Federal do Tocantins. Pesquisadora da Cátedra de Leitura Unesco/ii Ler PUC-Rio. E-mail: valeria.medeiros@uft.edu.br

2 Professora adjunta de Literaturas de Língua Inglesa na Licenciatura em Letras da Universidade Federal do Tocantins, Campus Araguaína. Atua no Programa de Pós-Graduação em Ensino de Língua e Literatura da mesma instituição. Pesquisadora da Cátedra Yeats de Estudos Irlandeses da Universidade de São Paulo. E-mail: andreamateus@uft.edu.br 


\section{INTRODUÇÃO}

A edição online do The New Yorker de 31 de março de 2019 celebrou os 50 anos de publicação do clássico distópico Slaughterhouse-Five (Matadouro cinco), de Kurt Vonnegut naquela semana. Emoldurada por uma cena da adaptação de grande sucesso para a TV de The Handmaid's Tale, de Margaret Atwood (1985), a crítica parte da premissa de que hoje vivemos em uma distopia da qual não há fuga possível considerando tudo o que está acontecendo em todo o mundo. Seguem-se reflexões acerca do romance de Atwood, da tematização do autoritarismo e anti-semitismo em The Plot Against America, de Philip Roth (2004) e a influência da esposa de Jane Vonnegut no trabalho do autor, passando por uma entrevista com Anthony Burgess, sobre a motivação para a escrita de A Clockwork Orange (1973). Em discussão está a ficção distópica direcionada ao público jovem, que ocupa seu espaço após um percurso histórico dos romances distópicos às origens dos universos pessimistas e sombrios em um futuro não muito distante após a II Guerra Mundial e a polarização entre EUA e a então URSS. Cada uma destas seções oferece uma perspectiva que permite uma leitura potencial destes cenários distópicos, mas a percepção de que o contexto atual sugere a concretização desta ficção de natureza especulativa, manifesta na popularização da transposição para a TV de O Conto da Aia, 34 anos depois de sua publicação é o fio condutor desta reflexão.

Neste sentido, nos parece incontornável retomar o modelar posfácio de Erich Fromm a 1984, de George Orwell (1949). Segundo Fromm, o romance é

the expression of a mood, and it is a warning. The mood it expresses is that of near despair about the future of man, and the warming is that unless the course of history changes, men all over the world will lose their most human qualities, will become soulless automatons, and will not even be aware of it ${ }^{3}$. (FROMM: 2003, p. 324)

A constatação da progressiva automatização do homem através da perda da dimensão que define sua humanidade - a liberdade para pensar - de fato leva a pensar no papel desta liberdade no percurso do pensamento ocidental como força que promoveria justamente o alcance da felicidade material e espiritual do indivíduo e da humanidade.

Entendemos que na base do pensamento de Fromm está o marco da crença na possibilidade de concretização deste projeto, a Revolução Francesa. A ela também se refere indiretamente Antonio Candido, em seu igualmente modelar texto "O direito à Literatura" (1995) para erguer seu argumento em defesa da literatura como um direito básico dada sua função humanizadora. Nos debrucemos então sobre este ponto de convergência nos escritos dos dois críticos, em contextos distintos.

Candido justifica sua argumentação através da contradição que permeia a história do Ocidente, qual seja, a promessa da racionalidade técnica - em clara referência ao Hu-

3 a expressão de um estado de espírito, e é uma advertência. O estado de espírito que ele expressa é próximo ao desespero acerca do futuro do homem, e a advertência é que, a não ser que o curso da história se altere, homens do mundo inteiro perderão suas qualidades mais humanas, se tornarão autômatos sem alma, e nem ao menos se darão conta disso (tradução nossa). 
manismo Científico do século XVIII que tem em Isaac Newton seu expoente maior - e a constatação nos dias atuais de que "o máximo de racionalidade técnica e de domínio sobre a natureza" (CANDIDO: 2012, p.16) não consegue possibilitar a igualdade social. Ao contrário, a contradição revela a ambiguidade da racionalidade humana enquanto força criadora e destruidora, na medida em que quanto maior o progresso industrial, menor a distribuição equitativa dos bens materiais uma vez que

em comparação a eras passadas chegamos a um máximo de racionalidade técnica e de domínio sobre a natureza. Isso permite imaginar a possibilidade de resolver grande número de problemas materiais do homem, quem sabe inclusive o da alimentação. No entanto, a irracionalidade do comportamento é também máxima, servida frequentemente pelos mesmos meios que deveriam realizar os desígnios da racionalidade. Assim, com a energia atômica podemos ao mesmo tempo gerar força criadora e destruir a vida pela guerra; com o incrível progresso industrial aumentamos o conforto até alcançar níveis nunca sonhados, mas excluímos dele as grandes massas que condenamos à miséria. (...) Portanto, podemos dizer que os mesmos meios que permitem o progresso podem provocar a degradação da maioria. (CANDIDO: 2012, p. 17)

Os momentos do passado e a exploração do homem como impedimento para a distribuição equânime das riquezas são nomeadas ("na Grécia antiga, por exemplo, (...)a técnica ainda não permitia superar as formas brutais de exploração do homem, nem criar abundância para todos", CANDIDO: 2012, p.17-18) ou referenciadas inequivocamente:

Mas em nosso tempo é possível pensar nisso, e no entanto pensamos relativamente pouco. Essa insensibilidade nega uma das linhas mais promissoras da história do homem ocidental, aquela que se nutriu das ideias amadurecidas no correr dos séculos XVIII e XIX, gerando o liberalismo e tendo no socialismo a sua manifestação mais coerente. (CANDIDO: 2012, p. 18)

A crença na remoção da ignorância e do despotismo conduziriam o homem à concretização das utopias renascentistas que estabelecem as bases do Humanismo nos séculos XVI e XVII e dão lugar à constatação de que "mesmo onde estes obstáculos foram removidos a barbárie continuou entre os homens." (CANDIDO: 2012, p. 18). Mais ainda, "nossa época", o século XX, "é profundamente bárbara, embora se trate de uma barbárie ligada ao máximo de civilização" porquanto não se possa vislumbrar modos de solucionar as desigualdades sociais, diferentemente do sonho dos "utopistas racionais" mas ao menos mitigar e reduzir tanto quanto possível a desigualdade e a injustiça. A Utopia, de Thomas More (1506) e A Cidade do Sol, de Tommaso Campanella (1602) ressoam distintamente quando Candido se refere ao racionalismo renascentista em oposição ao pensamento teocêntrico da Idade Média. Não por acaso, Erich Fromm se refere diretamente a ambas as obras e seus respectivos autores. 
Assim, a barbárie parece ter ocupado sempre espaço na história ocidental - cada tempo elegendo, obviamente, o seu bárbaro. No século XVIII, mais precisamente em 1794, o abade Gregório usa o termo "vandalismo" para repudiar, paradoxalmente, os danos causados pelos revolucionários franceses ao patrimônio que pertencia, de fato, ao povo francês (LOGEAY: s/d., p. 12-13). Em nosso tempo, episódios de agressões e repúdio a imigrantes se avolumam em uma Europa cada vez mais abalada por uma crise migratória reconhecida como mundial pelo encontro em setembro de 2016 de líderes de 20 países, o G20.

Mas que nova alegada ameaça é essa que se espelha em imagens difundidas a partir do século V? Que bárbaro é esse, ou melhor, bárbaro para quem - quem é o eu e quem é o outro no encontro entre culturas? Edward Gibbon, no célebre Declínio e queda do Império Romano publicado em 1952, descreve a fúria dos hunos e a ameaça à liberdade e à segurança que as chamadas Invasões Bárbaras representaram até a historiografia mais recente. Estes povos viriam a ser amalgamados na imagem de Átila, uma lenda em vida cujos adversários temiam a ponto de render-se sem combater, responsável por trazer a selvageria e a infelicidade às portas do civilizado mundo antigo (em enorme parte romano ou romanizado):

No desastroso período da queda do Império Romano, que pode ser justificadamente datada do reinado de Valente, a felicidade e a segurança de cada indivíduo era atacada, e as artes e obras de séculos rudemente desfiguradas pelos bárbaros da Cítia e da Germânia. A invasão dos hunos impeliu, nas províncias do Oriente, a nação gótica, que em menos de quarenta anos avançou do Danúbio ao Atlântico e abriu caminho, pelo sucesso de suas armas, às invasões de tantas tribos hostis, mais selvagens do que ela própria (GIBBON: 2005, p.446-7).

Quando Jacques Le Goff e Pierre Nora publicaram, em 1974, Faire de l'histoire, em três volumes, a coletânea - de autoria de um grupo de historiadores que convergiam em seus questionamentos de uma história positivista - foi recebida como manifesto-programa para uma nova orientação da história. O conjunto da proposta acentuava, respectivamente, novos objetos, novas abordagens, novos métodos. De modo geral, o problema poderia ser colocado nos termos da perda da convicção e do desaparecimento deste modelo de História do campo de inquietações, tanto dos chamados "novos historiadores", quanto dos pensadores contemporâneos em geral. O espaço da historiografia tradicional, hoje entendida como suposta correspondência ao real, vem sendo ocupado por perspectivas motivadas pelas implausibilidades desta escrita historiográfica convencional.

Estes tipos de experimentos historiográficos traduzem, de modo enfático, as reflexões epistemológicas, teóricas e metodológicas, que têm mobilizado teóricos e historiadores da literatura desde a década de 70. Nesta perspectiva, as Invasões Bárbaras não devem ser entendidas como grandes deslocamentos em massa de populações para destruir o Império Romano que caiu, de fato, por si só, corroído por contradições internas (VEYNE, 2009). Não nos cabe aqui aprofundar estas contradições, mas lançar alguma luz sobre as imagens criadas pelo fim de um mundo que deixa espaços, que poderão ser preenchidos por outros 
povos, guiados pela Nova História. Tomemos como exemplo, dentre as diversas tribos que avançaram sobre o Império Romano do Ocidente, intermitentemente, por mais de dois séculos, os vândalos. Estes não foram mais ou menos violentos ou destruidores do que os demais povos bárbaros. Eram cristãos arianos que perseguiram implacavelmente os católicos quando dominaram a África romana e, por isso, tiveram seu nome associado pelos intelectuais da Igreja Católica a um comportamento violentamente desprezível e à destruição de uma cultura ou bem alheio em retaliação. Apesar de os vândalos respeitarem as tradições romanas, sua cultura tornou-se sinônimo, e deu nome aos atos de depredação contra bens públicos. Mas se, no século V, o Império Romano perde suas províncias ocidentais, onde os bárbaros delimitam reinos; sua continuação, reduzida à sua metade oriental, é assegurada pela civilização bizantina. O que permanece (ainda que transformada gradativamente pela passagem do tempo) é a cultura ática, pois, em Roma, "a civilização, a cultura, a literatura, a arte e a própria religião provieram quase inteiramente dos gregos ao longo do meio milênio de aculturação; desde sua fundação, Roma, poderosa cidade etrusca, não era menos helenizada que outras cidades da Etrúria" (VEYNE: 2009, p.12-13). Foi Homero quem utilizou repetidamente na Ilíada a palavra barbarófono, àquele que fala como um bárbaro - mais especificamente os aliados dos troianos que falavam grego incorretamente, corrompendo a língua. Como os persas dominavam regiões do Oriente, os gregos associaram a região aos bárbaros e o Ocidente à civilização, um conceito que ainda persiste mesmo que de forma subliminar. Segundo Anne Bernet, no artigo intitulado "Bárbaro era quem não falava grego" (BERNET: s/d), apesar de habitantes de cidades-estado rivais, os gregos antigos eram conscientes de que para além da língua comum compartilhavam uma religião, um conjunto de valores - a forma como concebiam o universo, a política e a cidadania. Livre e civilizado, o modelo grego não integrava o estrangeiro. Não se tratava da xenofobia em sua feição atual, mas a ideia de uma superioridade cultural que não permitia a assimilação do diferente - mas que também não significava ignorá-lo. O xenos, grego de outra cidade, deveria ser respeitado, acolhido e honrado - uma vez que protegidos por Zeus Xenos e Atena Xênia porém seus valores e cultura não deveriam ser incorporados. O não-heleno, este não-grego que falava outra língua, ainda que não pudesse ser compreendido, continuava sem identidade e insignificante. Como vemos, cada tempo determina seu conceito de barbárie sem, contudo, excluir a ideia original da recusa ao diferente.

As linhas iniciais do conto de antecipação científica "A balela do balão" (The Balloon-Hoax, 1844) poderiam traduzir as convicções cientificistas do mundo representado por Edgar Allan Poe: "O grande problema está afinal resolvido! O ar, assim como a terra e o oceano foi dominado pela ciência e tornou-se uma estrada comum e conveniente para a humanidade. O Atlântico foi realmente atravessado por um balão!” (POE: 1981, 703-4). Esta preocupação com questões científicas do autor, balizado por ideias positivistas fundadas sobre o pressuposto do progresso como uma lei da história da humanidade, e da ciência como fundadora e condicionadora do crescente domínio da natureza e da promoção conco- 
mitante do homem, tornou-se hoje problemática. Questionados os discursos legitimadores que avalizavam o fascínio de Poe por um mundo meticulosamente construído pela lógica, desaparecidas as premissas e certezas que iluminavam a razão, perde espaço a atração pelo modelo positivo de realidade, sustentado pela crença em correlações e correspondências estáveis que conduzem ao desvendamento do enigma.

A promessa do conhecimento é o canto das sereias com que a ciência atrai Poe, e sua busca se torna o eixo em torno do qual seus escritos parecem girar. Para alcança-la entretanto, Poe acredita que é necessário algum princípio organizador. Elege então os ideais do progresso e a crença na ciência como método seguro de se conhecer a verdade, tão em voga no século XVIII; o resultado será um pensamento que se move vigorosa e paradoxalmente, buscando o eterno em meio ao temporal, equacionar razão e desrazão. Baudelaire, no necrológio que dedica a Poe, reconhecendo-se no autor e isentando-o da culpa por suas contradições, e de certo modo, das suas próprias, identifica a determinação pela busca da verdade na herança iluminista, o culto da razão como causa direta da incoerência:

Se querer conhecer a verdade a qualquer preço é um grande crime, ou pelo menos pode levar a grandes faltas, se a parvoice e a incúria são uma virtude e uma garantia de equilíbrio, creio que devemos ser muito indulgentes em relação a esses ilustres culpados, pois, filhos dos séculos XVIII e XIX, esse mesmo vício é imputável a todos nós (BAUDELAIRE: 1993, p.41).

O século XVIII desenvolveu uma resposta, filosófica e prática a esta busca por um sentido consequente para a modernidade. O projeto iluminista adotou a ideia de progresso que foi uma das mais comuns ao oitocentos, correspondendo a uma singular mobilização dos intelectuais iluministas no sentido do desenvolvimento da ciência objetiva. O triunfo da ciência e seu consequente domínio da natureza através da utilização do conhecimento acumulado - e produzido, por sua vez, pelo trabalho livre e criativo de indivíduos à procura da libertação do homem e da melhora da qualidade da qualidade de vida cotidiana - assegurava a superação da necessidade e das forças naturais.

A herança do século XVIII, remete a filósofos como Condorcet - também matemático - que fornece as bases do positivismo de Auguste Comte e cujo Esboço de um quadro do progresso histórico dos progressos do espírito humano é marcado por um extraordinário otimismo histórico, possuído "da extravagante expectativa de que as artes e as ciências iriam promover não somente o controle das forças naturais como também a compreensão do mundo e do eu, o progresso moral, a justiça das instituições e até a felicidade" (HABERMAS:1983, p.45). Condorcet defendeu ardorosamente a harmonia entre o progresso científico e o progresso moral da humanidade. Convencido da fé no poder que a razão possui de assegurar a felicidade e a igualdade dos homens, Condorcet procurou congregar a esperança baconiana de uma ciência que organizasse e reorganizasse o sistema social em seu conjunto. Com ele, o Século das Luzes prolonga a utopia técnica em visão messiânica: a sociedade dos sábios é chamada a ocupar um lugar privilegiado e a tornar-se o modelo da sociedade ideal. Sua obra mais conhecida, Esboço de um quadro histórico dos progressos do espírito humano, foi escrita após apresentar um projeto de Constituição para a França pós-revolucionária. 
Publicado em 1795, após sua morte na prisão em circunstâncias obscuras, a própria Convenção, que o havia condenado toda a tiragem de três mil exemplares da edição do livro foi distribuída nas escolas francesas.

A perspectiva de Condorcet é a de que os progressos do espírito humano fornecem o fio condutor da história. Um dos elementos constitutivos desta ideia é a certeza de que existe uma lei do progresso, entendendo-se por isto a necessidade, determinada por certos fatores, através da qual o homem, na sua história, passa por diversos estágios de desenvolvimento. Este desenvolvimento manifesta uma regularidade, que se apresenta no passado e é aplicável também ao futuro. A continuidade da história seria fundada nesta necessidade e traduzível pela superioridade dos estágios posteriores em relação aos anteriores. Ela define também a direção e o sentido da história, partindo da afirmação progressiva da razão humana e suas realizações. Desta forma, é a acumulação dos conhecimentos humanos que forma a dinâmica da história, e a ciência torna-se instrumento de conhecimento e ação. A natureza e a sociedade tornam-se, sob este ponto de vista, objeto da ação, racional, do homem, visando sua transformação. Se o critério de valor é a ideia de progresso, o século XVII é entendido por Condorcet como superior aos precedentes, pois é visto como a expressão de uma aliança entre ciência e política. Estabelecendo uma correspondência entre o desenvolvimento da razão, o aperfeiçoamento da humanidade e a construção de uma sociedade mais feliz, para Condorcet a política da ciência se reduziria à política para a ciência. O filósofo idealizava uma república das ciências na qual haveria uma simbiose entre saber e poder, porque o progresso do saber passa pelo poder político. Do mesmo modo, o interesse do Estado exigiria uma consulta aos sábios: assim como a ciência organizada tem necessidade da "proteção esclarecida do governo", da mesma forma o governo, para tirar partido da ciência, tem necessidade de consultar os sábios. Este estágio máximo de perfeição não poderia, ainda, ser interrompido; prova disso é que o Esboço é escrito no futuro. O progresso representa, enfim, a realização dos ideais da razão e a possibilidade de construir o futuro.

A influência mais determinante para o desenvolvimento de certos aspectos da doutrina positivista de Auguste Comte (1832) - mais especificamente a noção da criação de uma ciência social e de uma política científica - foi Condorcet, a quem se referia como seu imediato predecessor. Um dos pontos centrais da filosofia positiva, a ideia de que o progresso é uma norma da história da humanidade tanto quanto a fé "na eficácia das ciências da natureza e a possibilidade de criação de uma ciência da sociedade - já havia sido anteriormente esboçado por Condorcet”, segundo Maria Célia Simon (SIMON:1997, p.120). No entanto, a lei fundamental que Comte afirma ter descoberto, não somente origina-se na noção de progresso emblematizada por Condorcet, mas deve muito aos estágios do progresso do homem, delineados na obra do matemático francês. Na perspectiva do Esboço, uma verdadeira compreensão da história pode mostrar que, apesar das crises, a perfectibilidade humana se manifestou por um progresso geral. A história deste progresso é dividida no livro em dez épocas, que vão dos inícios hipotéticos ("Primeiro período: Os homens estão reunidos em povoados”) até a época presente, isto é, até o momento da Revolução Francesa ("Décimo período: dos futuros progressos do espírito humano”).

É possível ouvir distintamente a ressonância dos dez estágios do progresso do homem delineados por Condorcet na lei comtiana dos três estados, segundo a qual a espécie hu- 
mana, o espírito individual e as ciências perfazem uma trajetória histórica que passa de um estado teológico a um estado metafísico, até alcançar o terceiro e último estado, o positivo, no qual o espírito humano finalmente encontra a ciência, base de organização moral e intelectual da sociedade. Desta maneira, o estado positivo de Comte sacraliza, tanto quanto o nono período de Condorcet, quanto o século XVIII como aquele da perfeição. Ambos os conceitos estabelecidos dentro de uma noção excepcionalmente otimista da história da humanidade, o que não significa dizer naturalmente que a ideologia do progresso tenha encontrado unanimidade em seu tempo.

A esperança positiva da descoberta, graças ao ajuste entre raciocínio e observação, das leis efetivas dos fenômenos do universo, de suas relações fixas de sucessão e semelhança, renunciou à procura da origem e destino do universo. Este número, por sua vez, tenderia a ser progressivamente diminuído através do progresso da ciência. Os esforços do homem devem reduzir-se então ao domínio da "verdadeira observação, única base possível de conhecimentos verdadeiramente acessíveis sabiamente adaptados a nossas necessidades reais" (COMTE: 1983, p.147). Ou seja, pela observação e a previsão podemos construir uma base de conhecimentos. É, portanto, para a utilidade deste conhecimento que convergem estes dois aspectos. A previsão e o controle dos fenômenos estão voltados, em última análise, para o restabelecimento e realização de um programa universal que regulamentasse e regenerasse a vida humana, tanto privada quanto pública. Validado pela observação sistemática, o conhecimento é "o destino necessário de nossas especulações sadias", devendo ser não meramente acumulado, mas aplicado com o objetivo último de conduzir a humanidade ao progresso geral e ininterrupto, ao "aperfeiçoamento contínuo de nossa verdadeira condição individual ou coletiva, em lugar da vã satisfação de uma curiosidade estéril”, segundo o Catecismo Positivista (COMTE: 1983, p.147).

Inscrita conscientemente na onda contra-revolucionária e ultraconservadora que sucedeu à Revolução Francesa, o pensamento de Comte "só se torna efetivamente compreensível sobre o pano de fundo da sociedade francesa da primeira metade do século XIX, profundamente abalada pelos conflitos resultantes do processo de transformações econômicas e políticas posteriores à revolução de 1789" (SIMON: 1997, p.121). Deste modo, sua obra está pontuada por conceitos estreitamente relacionados à ordem e à estabilização social.

Nesse sentido, A Handmaid's Tale, que, como dito acima, publicado em 1985, pode ser lido como a constatação da falência deste projeto. É considerado como uma incursão de Margaret Atwood no gênero distópico da ficção científica, não sendo ela própria uma autora identificada diretamente com o universo $s c i$-fi. Ainda assim, é possível pensar na relação entre Atwood e suas antecessoras no gênero: escritoras mulheres que tomaram as rédeas dessa escrita tida até então como majoritariamente masculina, na escrita e no público, ao final dos anos 1960s. Autoras como a precursora Ursula K. Le Guin (1929-2018), Joana Russ (1937-2011), Marge Piercy (1936), e mais tardiamente Octavia Butler (1947-2006), entre outras, levaram a ficção especulativa ao encontro das questões feministas, encorpando o de- 
bate com a complexidade gerada pela liberdade narrativa de uma escrita que se desloca em eixos temporais e espaciais não convencionais.

A questão do sentido "extrapolativo" ou "futurístico" na ficção científica foi explorada por Le Guin em seu prefácio de 1976 de The Left Hand of Darkness, desvinculando seu trabalho de noções populares de que o gênero busca "prever o futuro". Segundo a autora, "the purpose of a thought-experiment, as the term was used by Schrödinger and other physicists, is not to predict the future (...) but to describe reality " (LE GUIN: 2016, p. 24). Atwood segue a mesma linha de pensamento de Le Guin, e sua obra nos indica claramente que a reflexão que suscita é sobre o presente.

Esperamos certas convenções de um romance de ficção científica, mas há muito espaço para subgêneros e todo tipo de experimentação narrativa pode ser encontrado. Expectativas podem tomar a forma de viagens espaciais, encontros com alienígenas, exploração das consequências dos avanços tecnológicos (robótica, inteligência artificial, mídias sociais, etc.) e caminham lado a lado com hipóteses humanísticas, desde seus primórdios. Podemos pensar em Frankenstein, escrito por uma autora mulher e publicado anonimamente em 1818, e que é tão "científico" quanto "filosófico"; ou retomar os comentários de Fromm, acima, ao 1984 de Orwell.

Fugindo de algumas dessas expectativas, o romance de Atwood opta por não criar um "universo paralelo", que nos romances de cunho distópico, parecem ser o "lugar nenhum" da etimologia da palavra "utopia”. É opção do gênero criar esse "lugar", entendido como a ilha inexplorada das narrativas de viagens ou o planeta na galáxia distante da ficção científica. Outra opção é tomar algum local do mundo real, geograficamente identificável ou não, em um suposto futuro distante, ainda que a precisão desse tempo não importe, como diria Le Guin. "Science Fiction is not predictive, it is descriptive" (LE GUIN: 2016, p. 24). Atwood segue essa linha, e aloca sua narrativa em uma república teocrática e militar, geograficamente nos EUA e com fortes traços do fundamentalismo cristão estadunidense, não existente em nosso mundo hoje, mas que talvez pudesse, num futuro qualquer.

Ainda assim, o "lugar nenhum" deve ser, convencionalmente, encontrado ou vivido por alguém, um personagem com quem o leitor possa se identificar, ainda que apenas por ser "humano", e que irá estranhar, assim como o leitor, a descoberta de uma nova realidade, de um novo mundo. Nosso personagem guia, em A Handmaid's Tale é a aia do título, cujo verdadeiro nome foi trocado por Offred, em referência ao seu novo patrão, Fred. Como qualquer leitor ou leitora da obra, sua chegada na realidade do novo regime é uma novidade, um estranhamento e uma abominação, acentuados pela história de vida da personagem, que aos poucos vai sendo revelada. Offred havia sido uma mulher de seu tempo, do nosso tempo, nem tão radicalmente envolvida no ativismo da mãe e da melhor amiga, nem tão apta a aceitar passivamente sua realidade de aia. É justamente nesta não radicalidade que reside o potencial de identificação: Offred é uma heroína muito próxima de qualquer um de nós, não apta a grandes atos de coragem ou sacrifício de sua integridade, até que o momento seguro aconteça.

4 "o propósito de um experimento hipotético, como o termo é utilizado por Schrödinger e outros físicos, não é prever o futuro (...) mas descrever a realidade.” (tradução nossa).

5 “A Ficção Científica não é preditiva, é descritiva." (tradução nossa). 
Ao leitor se apresenta, compacta na frase de abertura do romance, "We slept in what had once been the gymnasium" (ATWOOD: 2017, p.13) a mistura que continuará se repetindo, entre o cenário familiar e o estranhamento. Havia aquele lugar, mas ele já não é mais o mesmo. Uma nova ordem perverteu aquele cenário, o ginásio, que é, ao mesmo tempo, onde se dá a tortura do processo doutrinário e o catalizador de lembranças de outras angústias: a descoberta do sexo, a juventude e suas inquietações. A República de Gileade se impõe como uma utopia que buscaria neutralizar todas as angústias e incertezas, através de papéis pré-programados, criando um sofrimento psíquico ainda mais indizível. O cenário familiar (o ginásio escolar) é pervertido por uma ordem estranha e pelo medo e pelo receio das personagens. A narradora em primeira pessoa, Offred, em sua desorientação e receio, arremeda a própria experiência da leitura (cuja natureza é sempre o transporte), e amplifica a sensação do estranho-familiar freudiano.

O cenário atual da narrativa (que é permeada por flash-backs, pois Offred vive apenas de suas memórias) é a casa do Comandante e de sua esposa, com seus empregados e tarefas estabelecidas, onde tudo emula a normalidade de uma rotina doméstica forçada, a imposição do regime violenta as memórias e as identidades de seus servos, gerando um desconforto psicológico intenso nos personagens envolvidos, tanto oprimidos quanto opressores. $\mathrm{E}$ é neste cenário que a mente e a psique de Offred resiste ao controle imposto pelo ambiente prisional, higiênico, e vazio. É também neste cenário que, aos poucos, o suspense da descrição do ato sexual reprodutivo bizarro, da violência sexual programada e sacralizada se desnuda, e o preço pago pelas aias é a escravização completa de seu corpo e dos filhos gerados por ele. Aprendemos, junto com Offred, que todo o aparato estatal de propaganda e repressão violenta, necessários para manter a suposta paz utópica da República de Gileade, nada mais é que uma farsa hipócrita. Há senhores e há escravos, e o que diferencia essas relações é apenas a retórica da máquina estatal, transvestida de interpretações dúbias da religiosidade do texto bíblico.

Como prisioneira, Offred busca cada pequena oportunidade de sobrevivência: da manteiga que guarda para usar como hidratante à frase misteriosa deixada pela ocupante anterior de sua cela-quarto. É através dessas brechas que a resolução da trama irá se impor, ao seu tempo.

Ainda que trabalhe dentro do escopo da ficção científica, Atwood não partilha da criação de universos cuidadosamente talhados para a experiência do estranhamento, planetas com formas de vida alienígenas inesperadas, geografias hostis e leis da física que se subvertem, mas explora, como Orwell, o terror da tortura física e psicológica imposta por regimes totalitários, nos fazendo vivenciá-los através do percurso da leitura.

Tudo neste Conto é familiar e ao mesmo tempo deturpado. A mudança governamental veio com os sinais usuais que aprendemos na História de qualquer ascensão de regimes de exceção: alguns direitos específicos sendo revogados, o recrudescimento da vigilância em alguns grupos, e então, rapidamente, a barbárie se instala. Se em 1984 a barbárie é eco dos regimes totalitários anteriores à Segunda Grande Guerra, o conto de Atwood nos remete às histórias folclóricas de alerta ao perigo, algo como "Contos de precaução" (em inglês

6 “Dormíamos no que já havia sido um ginásio." (tradução nossa). 
Cautionary Tales) pois parece alertar para o perigo, hoje tão próximo, de uma retomada da perda de direitos e liberdades fundamentais.

Até aqui, procuramos explorar a convergência no pensamento de Candido (a inclusão da Literatura no conjunto de bens incompressíveis (ponto de vista do padre dominicano Louis-Joseph Lebret, que o crítico brasileiro utiliza para operacionalizar sua hipótese) ou direitos básicos extensivo a todos bem como "a alimentação, a moradia, o vestuário, a instrução, a saúde, a liberdade individual, o amparo da justiça pública, a resistência à opressão etc.” por sua função humanizadora (CANDIDO: 2012, p.22 - grifo nosso) e a leitura de Erich Fromm da distopia orwelliana como alerta à desumanização do homem a partir de um consenso entre o que chama de "utopias negativas". Sendo a natureza desse ponto "filosófica, antropológica e psicológica, e talvez religiosa" Fromm formula a pergunta: "can human nature be changed in such a way that man will forget his longing for freedom, for dignity, for integrity, for love - that is to say, can man forget that he is human? ${ }^{7}$ (FROMM: 2003, p. 329).

Ambos os críticos, como vimos, ancoram seus argumentos, em última análise, no projeto Iluminista de organização social em torno da ciência e na promessa de que "o sucesso constante da metodologia cientifica ao longo da história e especificamente sua capacidade de transformação "convidam a supor que proporcionará indefinitivamente um conhecimento cada vez melhor da realidade”. (CUPANI: 1985, p.23). Mais ainda, apontam para uma possível leitura do interesse renovado pela distopia como radicalização da razão criadora/ destruidora do homem, expondo a impossibilidade da racionalidade técnica se impor sobre a irracionalidade humana. A distopia permite a melhor compreensão do cenário atual (daí sua retomada) onde as desigualdades sociais não são erradicadas ou mitigadas. Ao contrário, o abismo entre os modos de vida de uma maioria miserável controlada por uma minoria abastada aumenta e, mais importante, as liberdades individuais são revogadas. Logo, sai da cena epistemológica e política o lema positivista "Amor, Ordem e Progresso" que traduzia a determinação de uma base racional e científica para promover uma reformulação intelectual e moral da sociedade através do estabelecimento do espírito positivo. Em seu lugar, entra o mote "Guerra é Paz; Liberdade é Escravidão; Ignorância é Força”. Lemos no universo rarefeito de 1984, de George Orwell - exemplar da ficção distópica na qual a constatação do fracasso do progresso Iluminista resulta na supressão do Esclarecimento (Aufklärung) kantiano da liberdade para pensar - um modo eficiente para erradicação do direito de expressão através de mecanismos de controle do indivíduo em todas as esferas da existência humana.

7 "pode a natureza humana ser modificada ao ponto do homem se esquecer do seu desejo de liberdade, de dignidade, de integridade, de amor - ou seja, pode o homem se esquecer de que é humano?” (tradução nossa). 


\section{REFERÊNCIAS}

ATMOOD, Margaret. A Handmaid's Tale. London: Vintage Books, 2017.

CANDIDO, Antonio. "O direito à literatura". IN: LIMA, Aldo de (org.). O direito à literature. Recife: Editora Universitária da UFPE, 2012.

BAUDELAIRE, Charles. Obras estéticas: filosofia da imaginação criadora. Petrópolis: Rio de Janeiro: Vozes, 1993.

BERNET, A. Bárbaro era quem não falava grego. História Viva: Bárbaros. n. 28. São Paulo: Duetto. s/d, p.18-23.

COMTE, Auguste. Curso de Filosofia Positiva; Discurso sobre o Espírito Positivo; Discurso Preliminar sobre o Conjunto do Positivismo; Catecismo Positivista. São Paulo: Abril Cultural, 1983.

CONDORCET, Jean-Antonio-Nicolas de Caritat, Marquis. Esboço de um quadro histórico dos progressos do espírito humano. Campinas: Unicamp, 1993

FROMM, Eric. "Afterword”, in ORWELL, George. Nineteen Eighty-Four. London: Penguin, 2003, pp. 324-337.

GIBBON, E. Declínio e queda do Império Romano. São Paulo: Companhia das Letras, 2005.

HABERMAS, Jürgen. Conhecimento e interesse. Rio de Janeiro: Guanabara, 1987.

LE GUIN, Ursula. The Left hand of Darkness. New York: Penguin, 2016.

LOGEAY, A. Os destruidores às portas de Roma. História Viva: Bárbaros. no. 28. São Paulo: Duetto. s/d. p.10-11.

POE, Edgar Allan. Ficção completa, poesia e ensaios. Rio de Janeiro: Nova Aguilar, 1981.

SIMON, Maria Célia. “O Positivismo de Comte”. In: REZENDE, Antonio (org.). Curso de filosofia. Rio de Janeiro: Jorge Zahar, 1997, p.120-132.

VEYNE, P. (org.). História da Vida Privada: do Império Romano ao ano mil. São Paulo: Companhia das Letras, 2009. 